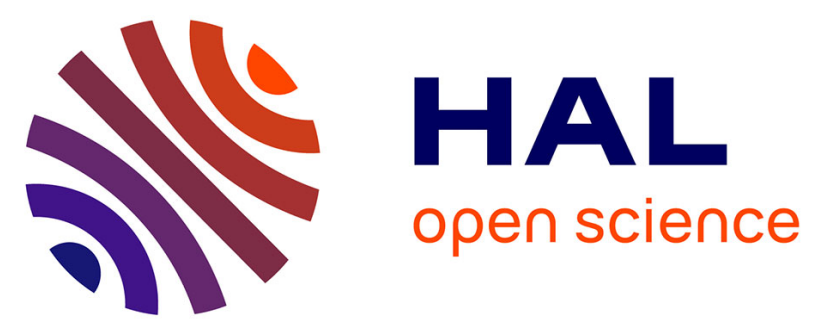

\title{
Risk of pacemaker implantation after radiotherapy for breast cancer: a study based on French nationwide health care database sample
}

Yassir Errahmani, Juliette Thariat, Jean Ferrieres, Loic Panh, Medea Locquet, Maryse Lapeyre-Mestre, Grégory Guernec, Marie Odile Bernier, Serge Boveda, Sophie Jacob

\section{To cite this version:}

Yassir Errahmani, Juliette Thariat, Jean Ferrieres, Loic Panh, Medea Locquet, et al.. Risk of pacemaker implantation after radiotherapy for breast cancer: a study based on French nationwide health care database sample. International Journal of Cardiology. Heart \& Vasculature, 2021, 38, pp.100936. 10.1016/j.ijcha.2021.100936 . hal-03546320

\section{HAL Id: hal-03546320 \\ https://hal.science/hal-03546320}

Submitted on 27 Jan 2022

HAL is a multi-disciplinary open access archive for the deposit and dissemination of scientific research documents, whether they are published or not. The documents may come from teaching and research institutions in France or abroad, or from public or private research centers.
L'archive ouverte pluridisciplinaire HAL, est destinée au dépôt et à la diffusion de documents scientifiques de niveau recherche, publiés ou non, émanant des établissements d'enseignement et de recherche français ou étrangers, des laboratoires publics ou privés.

\section{(ㅇ)(1) $\$$}

Distributed under a Creative Commons Attribution - NonCommercial - NoDerivatives $\mid 4.0$ 


\title{
Risk of pacemaker implantation after radiotherapy for breast cancer: A study based on French nationwide health care database sample
}

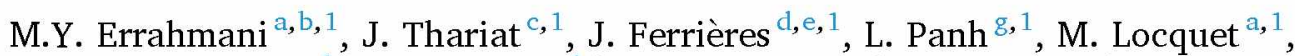 \\ M. Lapeyre-Mestre ${ }^{f, 1}$, G. Guernec ${ }^{\text {d, } 1}$, M.O. Bernier ${ }^{a, 1}$, S. Boveda ${ }^{\text {g, }}{ }^{\text {, S. Jacob }}{ }^{\text {a, }}, 1$ \\ ${ }^{a}$ Laboratory of Epidemiology, Institute for Radiation Protection and Nuclear Safety (IRSN), Fontenay-aux-Roses, France \\ ${ }^{\mathrm{b}}$ University Paris-Saclay, Gif-sur-Yvette, France \\ ${ }^{\mathrm{c}}$ Department of Radiotherapy, Centre de Lutte Contre le Cancer A. Baclesse, University of Caen Normandie, Caen, France \\ d INSERM, UMR 1295 - CERPOP Centre d'Epidémiologie et de Recherche en santé des POPulations, Toulouse, France \\ e Department of Cardiology, Toulouse Rangueil University Hospital (CHU), Toulouse, France \\ ${ }^{\mathrm{f}}$ Department of Medical and Clinical Pharmacology, CIC 1436, University of Toulouse 3, Toulouse, France \\ ${ }^{8}$ Heart Rhythm Management Department, Clinique Pasteur, Toulouse, France
}

\section{A R T I C L E I N F O}

\section{Keywords:}

Breast Cancer

Radiotherapy

Cardiac complications

Pacemaker

French national health insurance database

\begin{abstract}
A B S T R A C T
Background: Among cardiac complications of breast cancer radiotherapy (BC RT), there are very limited data on arrhythmia and conduction disorders, in particular severe cases requiring permanent pacemaker implantation (PPMI). Therefore, this exploratory study aimed to evaluate the risk of PPMI for BC patients treated with RT, compared with the general population and with BC patients not treated with RT.

Methods: The study was performed on a 1/97 representative sample of the French health care database (EGB database). Adult women with a first BC treated with or without RT between 2008 and 2016 were included, followed until 2018, and de novo PPMI were identified. We compared the PPMI incidence in BC cohort relative to the general population with standardized incidence ratio (SIR) and evaluated the risk of PPMI in RT patients compared to patients without RT with a competing risk survival analysis.

Results: A total of 3853 BCE patients were included. Among BC patients treated with RT, 28 PPMI cases were observed compared with 13 expected cases, corresponding to a SIR of 2.18 [95\% CI: 1.45-3.06]. For BC patients not treated with RT, the SIR was 1.01 [95\% CI: $0.40-1.90$ ]. Patients treated with RT showed a borderline significant higher risk of PPMI compared with those not treated with RT (subdistribution Hazard Ratio $=2.08,95 \%$ CI $0.87-4.97, \mathrm{p}=0.09$ ).

Conclusions: Our exploratory findings indicate that, over the last decade in France, BC patients treated with RT appeared to be at higher risk of PPMI than general population. Further studies are needed to expand on this topic.
\end{abstract}

\section{Introduction}

Radiotherapy (RT) is currently a standard of care for many breast cancers (BC). Although it generally provides a significant improvement in tumor control and significantly reduces the risk of cancer-related death several years after treatment, it also involves irradiation of the heart because of its anatomical position in the thoracic region. With the improvement of cancer management and survival of these patients, cardiac complications, which can occur many years after RT, have become an issue.

It is now known that an association exists between this type of exposure and cardiac complications: patients treated with breast RT until the 1990s had an increased long-term risk ( $>5-10$ years) of heart failure, coronary heart disease, myocardial infarction, and ultimately cardiovascular death [1]. Among late cardiac complications, coronary complications are currently the most described and best known. An association between cardiac radiation exposure and the occurrence of coronary events has been found in retrospective cohort studies of patients treated with BC RT, with follow-up periods ranging from a few years to more than 20 years $[2,3]$.

Unlike the study of cardiovascular mortality or coronary complications, cardiac arrhythmias and conduction disorders are almost absent

\footnotetext{
* Corresponding author.

E-mail address: sophie.jacob@irsn.fr (S. Jacob).

1 This author takes responsibility for all aspects of the reliability and freedom from bias of the data presented and their discussed interpretation.
} 
from research in the field of cardiac complications after RT. However, the tissue fibrosis induced by RT could be responsible for secondary nonspecific atrial, ventricular and coronary cardiac lesions which are the pathophysiological bed of arrhythmias or conduction disorders. Some case reports suggested a link between BC RT and atrioventricular block, a severe form of conduction system disorder for which permanent pacing is the therapy of choice $[4,5]$. Some cohort studies have shown that $\mathrm{BC}$ patients treated with RT had a higher risk of cardiac rhythm disorder or mortality for conductive disorders than BC patients not treated with RT $[6,7]$, but this higher risk was not observed in a study on arrhythmia and conduction disorders requiring of pacemaker or defibrillator implantations [8].

Although an association between BC RT and arrhythmias and/or conduction disorders has been suggested, more studies are needed to enhance knowledge on the eventual impact of RT. The spectrum of arrhythmias and devices is wide. Severe bradycardia treated with pacemaker implantations represents approximately 60000 cases per year in France $[9,10]$. As this baseline rate is quite high, it is important to understand if RT increases baseline risk of PPMI because it may imply substantial additional cases of "radiation-associated" pacemaker implantations.

In order to investigate specifically this potential cardiac complication of BC RT, we conducted an observational exploratory study on BC patients, in France 2008-2018, to assess the risk of permanent pacemaker implantation (PPMI) after RT, compared with the general population and compared with BC patients not treated with RT, using a representative sample of the French National Healthcare database.

\section{Methods}

\subsection{Data source}

The study was based on data from the Système National des Données de Santé (SNDS) [11], the national electronic health care database, and more specifically from the Echantillon Généraliste de Bénéficiaires (EGB), a 1/97th permanent representative sample from the whole population of the SNDS database. The SNDS includes claims data from 2003, for more than 66 million individuals (including 50 million adults), from birth (or immigration) to death, covering $99 \%$ of the total population, corresponding to the main health insurance schemes (general scheme for almost salaries, unemployed, and retired people; agricultural scheme for farmers, self-employed workers' scheme and several small specific schemes (teachers, parliamentarians, clergy ....). The EGB is a dynamic cohort sample which has been implemented in 2006 initially including individuals from the general insurance scheme, and has been progressively extended to other schemes from 2011. It contains anonymized data on demographics (gender, year of birth, date of death); long term diseases (LTD) resulting in full insurance coverage; all reimbursed outpatient healthcare encounters (visits, medical procedures, lab tests, drugs, medical devices); as well as hospital procedures and discharge diagnoses (including main diagnosis, related diagnosis, and as many associated diagnoses as necessary for one hospital discharge summary). Diagnoses identified in LTD and hospital discharges are coded according the 10th revision of the International Classification of Diseases (ICD-10). All medical procedures performed during each hospital stay and for outpatient care are encoded according to the French Common Classification of Medical Procedures (CCAM).

\subsection{Study population}

We conducted an observational study based on the population included in the EGB database including adult women beneficiaries, affiliated with the general insurance scheme, identified with a first BC between 2008 and 2016 and followed until December 31st 2018. BC were identified with long-term disease (LTD) with ICD-10 codes C50 (Malignant neoplasms of breast) or D05 (Carcinoma in situ of breast).
Date of BC diagnosis was defined as date of BC LTD. Surgery, radiotherapy and chemotherapy were identified using the French Common Classification of Medical Procedures (CCAM). The outcome, de novo PPMI performed at least one year after BC diagnosis, was identified with medical procedures codes in CCAM (the list of CCAM codes used to identify PPMI are available in Supplementary Material A). Patients with a history of BC or PPMI identified during at least 2 years before inclusion, corresponding to BC diagnosis, were excluded. Finally, patients with a follow-up $\geq 1$ year (time from BC diagnosis to either PM implantation or death or December 31st, 2018) were considered for analysis. Patients with a history of diabetes were identified by using either Long Term disease Codes (ICD 10 - Diabetes mellitus E10-E14) or ATC system (ATC code A10 - Drugs used in diabetes). Hypertension is not included in Long Term disease Codes and we identified patients with a history of treated hypertension with ATC system (ATC code $\mathrm{CO} 2$ Antihypertensive).

\subsection{Statistical analysis}

Continuous data are presented as mean values \pm standard deviation (SD) and categorical data as frequency counts and percentages. First, we compared the PPMI incidence in BC cohort, for patients treated with and without RT, relative to the general population, using standardized incidence ratio (SIR) with 95\% confidence intervals (CIs) [12]. The SIR was obtained by dividing the observed number of PPMI cases by the expected number of PPMI cases estimated from general population reference rates. Due to the lack of French registry for PPMI and annual reference rates of PPMI, we calculated these rates for adult women in the general population from the EGB database between 2008 and 2018, by age category ( $<40$ years old; 40-50; 60-70; 70-80; $>80$ ) and calendar period (1-year categories). Second, within the BC longitudinal cohort, we evaluated the risk of PPMI in BC patients treated with RT compared to patients without RT with a survival analysis. Considering that hazard of PPMI would change more as a function of age than as a function of time-on-study, we used attained-age as the time-scale, corresponding to the age of the patient at the time of PPMI or death or end of follow-up. We incorporated into our analysis the competing risk of death, which takes into account the fact that death precludes PPMI from ever occurring. This prevented the overestimation of probability of PPMI occurrence that could happen if death was not accounted for [13]. We evaluated the cumulative incidences for PPMI according to treatment group (with RT, without RT) and used Gray's test for comparison [14]. Finally, the risk of PPMI in BC patients according to treatment group was evaluated using a proportional subdistribution hazard regression model, with subdistribution Hazard Ratio (sd HR), to adjust for identified risk factors of PPMI while simultaneously accounting for competing risk by applying the Fine-Gray proportional subdistribution hazard analysis method [15]. In univariate analysis we considered the following variables: RT (vs. no RT), age, chemotherapy, diabetes and hypertension. In multivariate analysis, only variables with a p-value $<0.20$ were considered. Similar analysis was performed to identify risk factors of PPMI after RT. All the analyses were performed using SAS Enterprise Guide, version 4.3 and SAS version 9.4 .

\subsection{Ethical consideration}

Since this was a study of an anonymized database and had no influence on patient care, ethics committee approval was not required.

\section{Results}

\subsection{Patients}

The BC population consisted of 3853 individuals included at BC diagnosis between 2008 and 2016 (approximately 400 new BC patients included each year), with $77 \%$ of them treated with RT (Fig. 1). A 


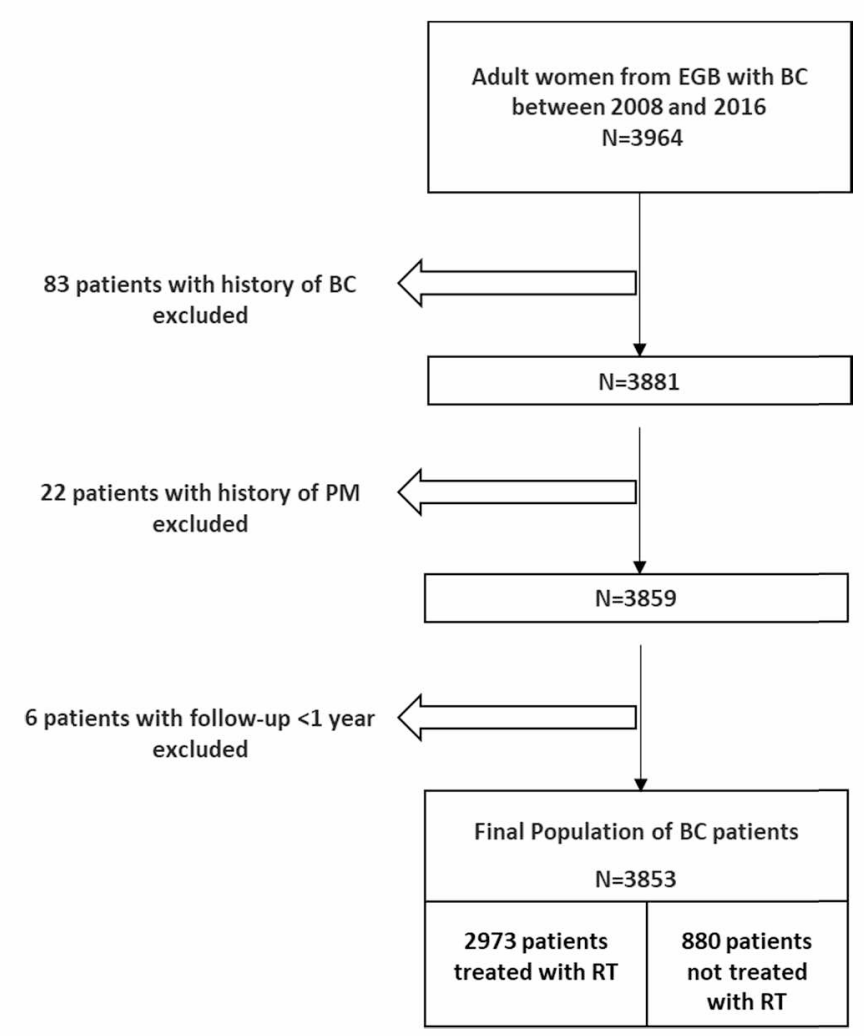

Fig. 1. Flow-chart of breast cancer participants in cohort study.

description of the population is presented in Table 1 . Patients treated with RT were younger ( 60.1 vs 65.9 years, p-value $<0.0001$ ), with $8 \%$ and $25 \%$ of individuals aged $>80$ years in the groups of RT and no RT,

Table 1

Characteristics of the 3853 BCE patients by radiotherapy status.

\begin{tabular}{|c|c|c|c|c|}
\hline & $\begin{array}{l}\text { Total } \\
\mathrm{N}= \\
3853\end{array}$ & $\begin{array}{l}\text { With RT } \\
N= \\
2973\end{array}$ & $\begin{array}{l}\text { Without } \\
\text { RT } \\
\mathrm{N}=880\end{array}$ & $P$-value \\
\hline \multicolumn{5}{|l|}{ Age at BC diagnosis, in years } \\
\hline Mean \pm SD & $\begin{array}{l}61.5 \pm \\
14.0\end{array}$ & $\begin{array}{l}60.1 \pm \\
13.2\end{array}$ & $\begin{array}{l}65.9 \pm \\
16.3\end{array}$ & $<0.0001$ \\
\hline$\geq 80$ years & $\begin{array}{l}469 \\
(12 \%)\end{array}$ & $247(8 \%)$ & $\begin{array}{l}222 \\
(25 \%)\end{array}$ & $<0.0001$ \\
\hline Surgery for BC & $\begin{array}{l}3459 \\
(90 \%)\end{array}$ & $\begin{array}{l}2891 \\
(97 \%)\end{array}$ & $\begin{array}{l}568 \\
(65 \%)\end{array}$ & $<0.0001$ \\
\hline Conservative & $\begin{array}{l}2561 \\
(74 \%)\end{array}$ & $\begin{array}{l}2328 \\
(81 \%)\end{array}$ & $\begin{array}{l}233 \\
(41 \%)\end{array}$ & \\
\hline Mastectomy & $\begin{array}{l}898 \\
(26 \%)\end{array}$ & $\begin{array}{l}563 \\
(19 \%)\end{array}$ & $\begin{array}{l}335 \\
(59 \%)\end{array}$ & \\
\hline Chemotherapy & $\begin{array}{l}1108 \\
(29 \%)\end{array}$ & $\begin{array}{l}945 \\
(32 \%)\end{array}$ & $\begin{array}{l}163 \\
(19 \%)\end{array}$ & $<0.0001$ \\
\hline Diabetes at $\mathrm{BC}$ diagnosis & $\begin{array}{l}451 \\
(12 \%)\end{array}$ & $\begin{array}{l}332 \\
(11 \%)\end{array}$ & $\begin{array}{l}119 \\
(14 \%)\end{array}$ & 0.06 \\
\hline $\begin{array}{l}\text { Treated hypertension at } \mathrm{BC} \\
\text { diagnosis }\end{array}$ & $\begin{array}{l}415 \\
(11 \%)\end{array}$ & $\begin{array}{l}309 \\
(10 \%)\end{array}$ & $\begin{array}{l}106 \\
(12 \%)\end{array}$ & 0.17 \\
\hline Death & $\begin{array}{l}565 \\
(15 \%)\end{array}$ & $\begin{array}{l}330 \\
(11 \%)\end{array}$ & $\begin{array}{l}235 \\
(27 \%)\end{array}$ & $<0.0001$ \\
\hline PPMI & $\begin{array}{l}35 \\
(0.91 \%)\end{array}$ & $\begin{array}{l}28 \\
(0.94 \%)\end{array}$ & $\begin{array}{l}7 \\
(0.79 \%)\end{array}$ & 0.68 \\
\hline $\begin{array}{l}\text { Duration between BC } \\
\text { diagnosis/RT and PPMI, in } \\
\text { months (mean } \pm \text { SD) }\end{array}$ & $4.1 \pm 2.1$ & $3.9 \pm 2.3$ & $4.8 \pm 1.1$ & 0.20 \\
\hline $\begin{array}{l}\text { Follow-up*, in years (mean } \pm \\
\text { SD) }\end{array}$ & $5.8 \pm 2.7$ & $5.8 \pm 2.6$ & $5.5 \pm 2.8$ & 0.0003 \\
\hline
\end{tabular}

BC Breast Cancer; RT Radiotherapy; PPMI Permanent pacemaker implantation; SD standard deviation.

* Follow-up is stopped at PPMI, or death or December 31st 2018. respectively (p-value $<0.0001$ ), more often treated with a primary surgery ( $97 \%$ vs. $65 \%, \mathrm{p}<0.0001$ ) and received chemotherapy in a higher proportion ( $32 \%$ vs. $19 \%$, p-value $<0.0001)$. The frequency of diabetes and treated hypertension was not statically significant between both groups ( $11 \%$ vs $14 \%, \mathrm{p}=0.06 ; 10 \%$ vs. $12 \%, \mathrm{p}=0.17$ respectively). Mean follow-up was slightly longer among patients with RT (5.8 years vs. 5.5 years, $p=0.0003$ ), but more than $50 \%$ of patients were followed at least 5 years in both RT and without RT group. We observed less death in the RT group ( $11 \%$ vs. $27 \%$, p-value $<0.0001$ ). A total of 35 PPMI were observed during follow-up in BC population: 28 in the RT group and 7 among patients without RT (0.94\% vs $0.79 \%$ respectively, $\mathrm{p}$ $=0.68$ ), and the duration between BC diagnosis and PPMI was lower among RT patients, but this difference was not statically significant (3.9 years vs. 4.8 years, $\mathrm{p}=0.20$ ).

\subsection{Comparison with general population (SIR)}

The annual incidence rates of PPMI estimated from the EGB-based general population are presented in the Supplementary Material B. The 2973 BCE patients treated with RT accrued a total of 24619 personyears during follow-up. Among them, 28 cases of PPMI were observed, compared with 12.9 expected cases of PPMI based on reference rates in general population compared with, yielding a significant SIR of 2.18 (95\% CI 1.45-3.06) (Table 2). In the group of patients without RT, the SIR was not significantly different from 1 (7 observed cases of PPMI compared with 7.0 expected cases, SIR $=1.01$ ( $95 \%$ CI 0.40-1.90)). By combining both treatment groups, we observed 35 PPMI among the 3085 BCE patients. The number of PPMI expected was 19.9. The SIR for PPMI in BC patients was 1.76 (95\% CI 1.22-2.39).

\subsection{Comparison with BC patients without $R T$ (sd HR)}

The cumulative incidence curves of PPMI for BC patients treated with and without RT are presented in Fig. 2. There was a significant difference (Gray's test p-value $=0.014$ ) between both groups for the overall follow-up. In particular for patients with attained age of 90 years old, cumulative incidence of PPMI was 2.5 times higher in patients treated with RT than in patients not treated with RT ( $4.46 \%$ vs. $1.71 \%$ ). Univariate analysis of PPMI risk based on subdistribution hazard regression model showed that age at $\mathrm{BC}$ diagnosis was a significant risk factor of PPMI (Table 3). No effect of chemotherapy was observed (sd_HR $=0.77(0.31-1.93)$ ). For diabetes and hypertension, risks above one were observed but not significant (sd_HR $=1.60(0.72-3.48)$, sd_HR $=1.24(0.52-2.98)$ respectively). In multivariate analysis, after adjustment on age at BC diagnosis, we could observed a borderline significant trend to an increased risk of PPMI associated with RT (sd_HR $=2.08$ (0.87-4.97), $\mathrm{p}=0.09$ ). Among patients treated with $\mathrm{RT}$, similarly to analysis of the whole cohort, no other risk factors than age was identified at a statistically significant level (Table 4).

Table 2

Standardized incidence ratio of PPMI according to radiotherapy status.

\begin{tabular}{clllll}
\hline & $\begin{array}{l}\text { Number of } \\
\text { individuals }\end{array}$ & $\begin{array}{l}\text { Person- } \\
\text { years }\end{array}$ & $\begin{array}{l}\text { Number of } \\
\text { observed } \\
\text { PM }\end{array}$ & $\begin{array}{l}\text { Number of } \\
\text { expected } \\
\text { PM }\end{array}$ & $\begin{array}{l}\text { SIR* }^{*}(95 \% \\
\text { CI) }\end{array}$ \\
\hline $\begin{array}{c}\text { All BC } \\
\text { patients } \\
\text { With RT }\end{array}$ & 3853 & 24,619 & 35 & 19.85 & $\begin{array}{l}1.76 \\
(1.22-2.39) \\
2.18\end{array}$ \\
Without & 880 & 19,201 & 28 & 12.86 & $\begin{array}{l}(1.453 .06) \\
\text { RT }\end{array}$ \\
\hline
\end{tabular}

* Standardized incidence ratio (SIR) standardized on age and calendar year; 95\% CI Confidence Interval; RT radiotherapy; PPMI Permanent Pacemaker implantation; BC Breast Cancer. 


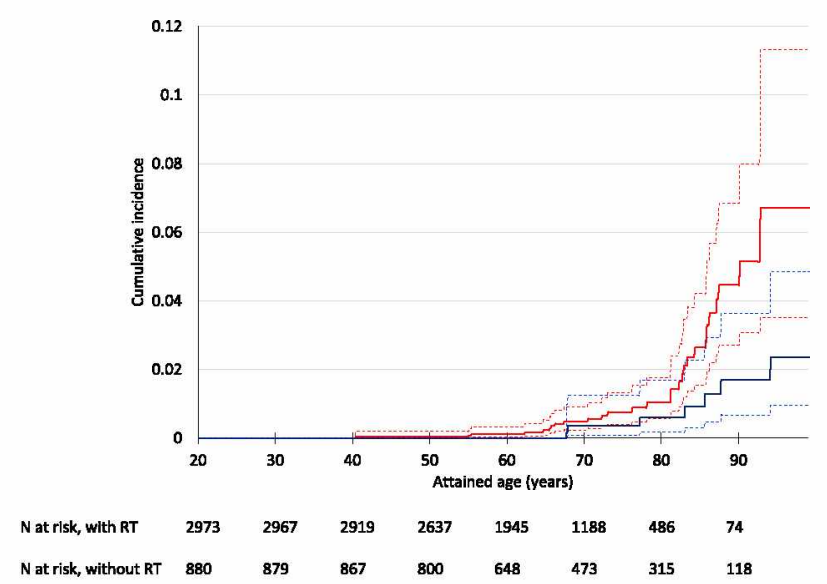

Fig. 2. Cumulative incidence of PPMI with attained age as time scale, according to BC treatment group, red for patients with RT, blue for patients without RT. Dotted lines for 95\% confidence interval. P-value for unadjusted Gray's test is $\mathrm{p}=0.0136$. (For interpretation of the references to colour in this figure legend, the reader is referred to the web version of this article.)

Table 3

Analysis of RT treatment and other risk factors of PPMI based on Fine and Gray's sub-distribution hazard model for PM implantation, with attained age as time scale.

\begin{tabular}{|c|c|c|c|c|c|}
\hline & & $\begin{array}{l}\text { sd HR }(95 \% \\
\text { CI) }\end{array}$ & $\mathrm{p}$-Value & $\begin{array}{l}\text { sd HR }(95 \% \\
\text { CI) }\end{array}$ & $\begin{array}{l}\mathrm{p}- \\
\text { Value }\end{array}$ \\
\hline RT treatment & & & & & 0.09 \\
\hline Without RT & $0.79 \%$ & 1.00 & & 1.00 & \\
\hline With RT & $0.94 \%$ & $\begin{array}{l}2.43 \\
(1.05-5.63)\end{array}$ & 0.038 & $\begin{array}{l}2.08 \\
(0.87-4.97)\end{array}$ & \\
\hline $\begin{array}{l}\text { Age at BC } \\
\text { diagnosis, in } \\
\text { years (mean } \pm \\
\text { SD) }\end{array}$ & $\begin{array}{l}77.2 \\
\pm 12.9\end{array}$ & $\begin{array}{l}0.97 \\
(0.95-0.98)\end{array}$ & $<0.0001$ & $\begin{array}{l}0.97 \\
(0.95-0.99)\end{array}$ & 0.0012 \\
\hline \multicolumn{6}{|l|}{$\begin{array}{l}\text { Treated } \\
\text { hypertension } \\
\text { at BC diagnosis }\end{array}$} \\
\hline No & $0.84 \%$ & 1.00 & & & \\
\hline Yes & $1.45 \%$ & $\begin{array}{l}1.24 \\
(0.52-2.98)\end{array}$ & 0.63 & & \\
\hline \multicolumn{6}{|l|}{$\begin{array}{c}\text { Diabetes at } \mathrm{BC} \\
\text { diagnosis }\end{array}$} \\
\hline No & $0.79 \%$ & 1.00 & & & \\
\hline Yes & $1.77 \%$ & $\begin{array}{l}1.60 \\
(0.72-3.48)\end{array}$ & 0.25 & & \\
\hline \multicolumn{6}{|l|}{ Chemotherapy } \\
\hline No & $1.09 \%$ & 1.00 & & & \\
\hline Yes & $0.45 \%$ & $\begin{array}{l}0.77 \\
(0.31-1.93)\end{array}$ & 0.57 & & \\
\hline
\end{tabular}

sd HR(95\% CI): sub-distribution Hazard Ratio with 95\% Confidence interval; RT Radiotherapy; BC Breast Cancer; PPMI: permanent pacemaker implantation.

\section{Discussion}

This investigation on the risk PPMI after BC RT has two main findings. First, during the period 2008-2018, we could detect a significantly twice higher incidence of PPMI among patients treated with RT than in the general population, whereas BC patients not treated with RT had similar incidence of PPMI than general population. Second, with a mean follow-up of 5.8 years among BC patients, we could observe a borderline significant trend to a 2 -fold increased risk of PPMI for BC patients treated with RT compared with BC patients not treated with RT.

Previous studies have investigated the risk of cardiac arrhythmias and bradycardia including conduction disorders after BC RT with different endpoints. In a cohort of 746 BCE patients (all treated with chemotherapy, $75 \%$ treated with RT), with a follow-up of 10 years, it was observed that patients treated with RT had higher occurrence of arrhythmia or conduction disorders than patients without RT (3.2\% vs. $0 \%$, p-value $=0.01$ ) [7]. Another study compared 330 patients treated with RT for BC with 4802 patients without RT and found no significant difference in the incidence of conduction disorders, but mortality due to conduction disorders was higher in the group with RT than in the group without RT (HR $=2.77$ [0.95-8.06]) [6]. More similarly to our study, severe arrhythmias and conduction disorders requiring pacemaker or defibrillator implantations were analyzed in a retrospective Danish study of 44,423 BCE patients included between 1982 and 2005, with a median follow-up of 11 years [8]. In contrast with our study, Danish study did not show a higher risk of PM or defibrillator implantations for the RT group compared to the general Danish population (SIR $=1.05$ (0.91-1.22)). Many reasons could explain such a difference. First, we focused our analysis on PM implantations in order to investigate severe bradycardia exclusively. By combining PM and defibrillators, Danish study analyzed together cardiac implantable electronic devices (CIED) with different functions and completely different indications (i.e., bradycardia and ventricular arrhythmias...), which may have induced bias in their results. Another point is about the estimation of the expected number of cases, and thus in the evaluation of the SIR. In the Danish study, reference rates were those from the Danish Pacemaker and ICD Registry on a very long period between 1982 and 2014 and the estimation of expected number of PM or defibrillator implantations was based on five-year calendar-time rates which may have provided unprecise rates. A strength of our study is that we used the national EGB database, a representative sample of the whole population living in France, for estimation of reference incidence rates of PPMI. Based on a unique database, we could keep exactly the same definition of the event (de novo PPMI) within the general population and within the BC population. Incidence rates of PPMI could thus be evaluating precisely by age category and year. For comparison of CIED risk between BC patients treated with or without RT, the Danish study evaluated the ratio of SIR between both groups and did not show neither a significant difference with an Incidence Rate Ratio-IRR of 1.13 (0.93-1.38). Such approach is based again on the estimation of SIR discussed above. In our study, we used a different approach based on survival analysis performed in the BC cohort. A strength of our study was to perform this survival analysis with the competing risk analysis which allowed taking into precisely the important number of patients who died during follow-up. Our results provided a borderline significant hazard ratio of $2.08(0.87-4.97)$ which

Table 4

Analysis of risk factors of PPMI after RT based on Fine and Gray's sub-distribution hazard model for PPMI with attained age as time scale.

\begin{tabular}{|c|c|c|c|c|c|c|}
\hline & \multirow{2}{*}{$\begin{array}{l}\text { PPMI } \\
\mathrm{N}=28\end{array}$} & \multirow{2}{*}{$\begin{array}{l}\text { No PPMI } \\
N=2945\end{array}$} & \multicolumn{2}{|l|}{ Univariate analysis } & \multicolumn{2}{|c|}{ Multivariate analysis } \\
\hline & & & sd HR (95\% CI) & p-Value & sd HR (95\% CI) & p-Value \\
\hline Age at BC diagnosis, in years & $71.3 \pm 12.4$ & $60.1 \pm 13.0$ & $0.97(0.95-0.99)$ & 0.0016 & $0.97(0.95-0.99)$ & 0.017 \\
\hline Treated hypertension at $\mathrm{BC}$ diagnosis & $2(7 \%)$ & $307(10 \%)$ & $0.43(0.10-1.79)$ & 0.20 & $0.46(0.11-1.92)$ & 0.29 \\
\hline Diabetes at $\mathrm{BC}$ diagnosis & $5(18 \%)$ & $327(11 \%)$ & $1.17(0.44-3.09)$ & 0.75 & & \\
\hline Chemotherapy & $5(18 \%)$ & $940(32 \%)$ & $0.87(0.34-2.22)$ & 0.77 & & \\
\hline
\end{tabular}

sd HR(95\% CI): sub-distribution Hazard Ratio with 95\% Confidence interval; RT Radiotherapy; BC Breast Cancer; PPMI: permanent pacemaker implantation 
is concordant with the higher occurrence of PPMI observed with SIR estimation, and strengthen our results.

Another study estimated the SIR of CIED in patients with Hodgkin lymphoma between 1969 and 1998, treated with mediastinal RT with a mean follow-up of 14.7 years [16], which provided a comparable result to our, with a SIR for requiring a pacemaker or defibrillator of 1.90 (1.70-2.21) compared to the general US population. However, these patients were treated for Hodgkin Lymphoma that induced higher exposure to the heart than BC RT and could thus lead to higher risks than those expected after BC RT, under the hypothesis of an established dose-response relationship. However, the association between cardiac dose and cardiac arrhythmia or conduction disorders after mediastinal $\mathrm{RT}$ is far to be clear as it was poorly studied. In a small cohort of lung cancer patients, arrhythmic events showed only borderline significant associations with heart dose $(p=0.051)$ [17]. No data on cardiac dosimetry is available in the EGB database, and we could not evaluate the impact of cardiac exposure on the risk of PPMI.

The occurrence of cardiac arrhythmias and conduction disorders after RT is usually associated with fibrosis of the conduction pathways, or nodal structures (sinus and atrioventricular nodes) due to microvascular damage. The tissue fibrosis induced by RT could be responsible for non-specific secondary cardiac lesions at the atrial, ventricular and coronary levels, which are the basis for arrhythmias and bradycardia. A study tested the hypothesis of an association with atrial dose in a population of 112 patients treated with radiotherapy for lung cancer, followed on average for 9 years, among whom 12 arrhythmic events have been identified [17]. This study showed a relatively weak association with the dose to the right atrium $(\mathrm{p}=0.082)$ which could be a proxy of the dose to the sino-atrial node. Studies that have analyzed the impact of cardiac dosimetry on potentially critical sub-structures for arrhythmias such as the sino-atrial node or the atrioventricular node are rare [18]. However, these structures can be located, with some uncertainty, on the RT Computed Tomography and could therefore provide information on the association between cardiac exposure and the risk of arrhythmia [19].

It is well known that the indications for PPMI are strongly associated with age. In general population, higher PM incidence in elderly populations has previously been observed $[10,20]$ and was also observed in our study based on EGB. Focusing on BC patients, we could observe that cumulative incidence of PPMI was higher in elderly BC patients treated with RT than in elderly patients not treated with RT (cumulative incidence of PPMI for attained age of 90 years old: $4.5 \%$ vs. $1.7 \%$ ). As expected, age at inclusion / BC diagnosis was a risk factor of PPMI in our cohort, but even more when patients had received RT. Could this be due to a fragility of the cardiac tissue in older patients, therefore more vulnerable to the direct action of X-rays? This point needs further investigations.

\section{Limitations}

Our exploratory analysis was based on small sample size. We worked on the EGB database which involved limited size of BC population and consequently small number of observed PPMI in this population. The spectrum of arrhythmias and devices could be expanded using these claims-based registry-data, but in this study we wanted to focus on PPMI first. With a study period of one decade $2008-2018$, we had a relatively short follow-up that limited the number of observed cases of PPMI after BC. Despite these limits, a strength of the EGB database is the exhaustive description of the general population in terms of age distribution during the study period. It allowed quantifying precisely the expected cases of PPMI and then the SIRs. Further analysis on the whole SNDS database could provide a larger cohort with increased number of PPMI events and increased statistical power. The laterality of breast cancer, as a proxy of cardiac exposure to ionizing radiation during radiotherapy, may have a significant impact on the occurrence of subsequent cardiac conduction disorders, in particular PPMI. However, none of this information is available in EGB database (nor in the whole SNDS database) and we could not examine whether there was a difference in the frequency of PPMI between left and right BC radiotherapy. Such information would be available only by crossing a clinical BC RT cohort containing information on laterality and cardiac absorbed doses with the SNDS database containing information on PPMI. Because of the lack of sensitivity for PPMI indication in the EGB databases, this information was not presented. However, without information on diagnosis and indication of PPMI, the reliability of our endpoint PPMI was not altered as it was based on an exhaustive list of medical procedure codes specific of pacemaker implantation (list of CCAM codes presented in Supplementary Material A). Moreover, our sample was small and we did not deeply explore cardiovascular background of this BC patient population except for diabetes and treated hypertension. No significant impact of diabetes and hypertension on PPMI risk was observed, but this could partly be explained by the limited size of our sample. In addition, it is now known that BC RT can induce cardiac complications, in particular for patients with history of cardiovascular disease and cardiac risk factors patients. As a consequence, patients treated without RT may have a potentially different profile with a higher baseline risk of cardiovascular disease compared to patients treated with RT. In our study, we could not detect such difference, except for age at BC diagnosis, but in further studies such difference may have significant impact on results and should be taken into account in order to evaluate the impact of RT. Thus, combining cardiac dosimetry information with detailed prior cardiac risk factors information remain important in order to refine potential relationship between the risk of PPMI and cardiac exposure of BC patients treated with RT and identify 'high risk' patient profile, in large clinical cohorts.

\section{Conclusion}

In this exploratory study, we could observe that adjuvant radiotherapy as practiced in France during the last decade may increase the risk of PPMI for BC patients. This remains to be further investigated in larger cohorts, with details on laterality, cardiac exposure and cardiovascular background.

\section{Declaration of Competing Interest}

The authors report no relationships that could be construed as a conflict of interest.

\section{Acknowledgement}

This work was supported by the French Working Group on Cardiac Pacing and Electrophysiology of the French Society of Cardiology [Grant number 2018-15000-QV].

\section{Appendix A. Supplementary material}

Supplementary data to this article can be found online at https://doi. org/10.1016/j.ijcha.2021.100936.

\section{References}

[1] M. Clarke, R. Collins, S. Darby, C. Davies, P. Elphinstone, V. Evans, J. Godwin, R. Gray, C. Hicks, S. James, E. MacKinnon, P. McGale, T. McHugh, R. Peto, C. Taylor, Y. Wang, Effects of radiotherapy and of differences in the extent of surgery for early breast cancer on local recurrence and 15-year survival: an overview of the randomised trials, Lancet 366 (9503) (2005) 2087-2106, https:// doi. org/10.1016/S0140-6736(05)67887-7.

[2] S.C. Darby, M. Ewertz, P. McGale, A.M. Bennet, U. Blom-Goldman, D. Bronnum C. Correa, D. Cutter, G. Gagliardi, B. Gigante, M.B. Jensen, A. Nisbet, R. Peto, K. Rahimi, C. Taylor, P. Hall, Risk of ischemic heart disease in women after radiotherapy for breast cancer, N. Engl. J. Med. 368 (11) (2013) 987-998, https:// doi.org/10.1056/NEJMoa1209825.

[3] V.A. van den Bogaard, B.D. Ta, A. van der Schaaf, A.B. Bouma, A.M. Middag, E. J. Bantema-Joppe, L.V. van Dijk, F.B. van Dijk-Peters, L.A. Marteijn, G.H. de Bock, 
J.G. Burgerhof, J.A. Gietema, J.A. Langendijk, J.H. Maduro, A.P. Crijns, Validation and Modification of a Prediction Model for Acute Cardiac Events in Patients With Breast Cancer Treated With Radiotherapy Based on Three-Dimensional Dose Distributions to Cardiac Substructures, J. Clin. Oncol.: Off. J. Am. Soc. Clin. Oncol. 35 (11) (2017) 1171-1178, https://doi.org/10.1200/JCO 2016.69.8480.

[4] F. Messina, P. Romano, M. Paino, S. Crosca, Long-term complication of the thoracic radiation in breast cancer: An complete atrioventricular block case, Int. J. Cardiol. 202 (2016) 5-6, https://doi.org/10.1016/j.jicard.2015.08.149.

[5] M.S. Slama, D. Le Guludec, C. Sebag, A.R. Leenhardt, J.M. Davy, D.E. Pellerin, L. H. Drieu, J. Victor, C. Brechenmacher, G. Motte, Complete atrioventricular block following mediastinal irradiation: a report of six cases, Pacing Clin. Electrophysiol.: PACE 14 (7) (1991) 1112-1118, https://doi.org/10.1111/j.1540-8159.1991. tb02842.x.

[6] H.W. Leung, A.L. Chan, C.H. Muo, Late cardiac morbidity of adjuvant radiotherapy for early breast cancer - A population-based study, J. Cardiol. 67 (6) (2016) 567-571, https://doi.org/10.1016/j.jjcc. 2015.07.009.

[7] S.P. Wu, M. Tam, R.M. Vega, C.A. Perez, N.K. Gerber, Effect of Breast Irradiation on Cardiac Disease in Women Enrolled in BCIRG-001 at 10-Year Follow-Up, Int. J. Radiat. Oncol. Biol. Phys. 99 (3) (2017) 541-548, https://doi.org/10.1016/j. ijrobp. 2017.06.018.

[8] J.C. Rehammar, J.B. Johansen, M.B. Jensen, L. Videbaek, O.D. Jorgensen, E. Lorenzen, M. Ewertz, Risk of pacemaker or implantable cardioverter defibrillator after radiotherapy for early-stage breast cancer in Denmark, 1982-2005, Radiother. Oncol.: J. Eur. Soc. Therapeut. Radiol. Oncol. 122 (1) (2017) 60-65, https://doi.org/10.1016/j.radonc. 2016.08.024.

[9] M.J.P. Raatikainen, D.O. Arnar, K. Zeppenfeld, J.L. Merino, K. H. Kuck, G. Hindricks, Current trends in the use of cardiac implantable electronic devices and interventional electrophysiological procedures in the European Society of Cardiology member countries: 2015 report from the European Heart Rhythm Association, Europace: Eur. Pacing Arrhythmias Cardiac Electrophysiol.: J. Working Groups Cardiac Pacing Arrhythmias Cardiac Cell. Electrophysiol. Eur. Society Cardiol. 17 (suppl 4) (2015) iv1-iv72.

[10] M.J. Raatikainen, D.O. Arnar, K. Zeppenfeld, J.L. Merino, F. Levya, G. Hindriks, K H. Kuck, Statistics on the use of cardiac electronic devices and electrophysiological procedures in the European Society of Cardiology countries: 2014 report from the European Heart Rhythm Association, Europace: Eur. Pacing Arrhythmias Cardiac Electrophysiol.: J. Working Groups Cardiac Pacing Arrhythmias Cardiac Cell. Electrophysiol. Eur. Society Cardiol. 17 (Suppl 1) (2015) i1-i75, https://doi.org/ 10.1093/europace/euu300.

[11] P. Tuppin, J. Rudant, P. Constantinou, C. Gastaldi-Menager, A. Rachas, L de Roquefeuil, G. Maura, H. Caillol, A. Tajahmady, J. Coste, C. Gissot, A. Weill,
A. Fagot-Campagna, Value of a national administrative database to guide public decisions: From the systeme national d'information interregimes de l'Assurance Maladie (SNIIRAM) to the systeme national des donnees de sante (SNDS) in France, Rev. Epidemiol. Sante Publique 65 (Suppl 4) (2017) S149-S167, https://doi.org/ 10.1016/j.respe. 2017.05,004.

[12] N. Breslow, N. Day, Statistical Methods in Cancer Research Volume II, Design Anal. Cohort Stud. (1987).

[13] P.C. Austin, D.S. Lee, J.P. Fine, Introduction to the Analysis of Survival Data in the Presence of Competing Risks, Circulation 133 (6) (2016) 601-609, https://doi.org/ 10.1161/CIRCULATIONAHA.115.017719.

[14] R.J. Gray, A Class of K-Sample Tests for Comparing the Cumulative Incidence of a Competing Risk, Ann. Stat. 16 (3) (1988) 1141-1154.

[15] J.P. Fine, R.J. Gray, A Proportional Hazards Model for the Subdistribution of a Competing Risk, J. Am. Stat. Assoc. 94 (446) (1999) 496-509, https://doi.org/ $10.2307 / 2670170$.

[16] S.L. Galper, J.B. Yu, P.M. Mauch, J.F. Strasser, B. Silver, A. Lacasce, K.J. Marcus, M. A. Stevenson, M.H. Chen, A.K. Ng, Clinically significant cardiac disease in patients with Hodgkin lymphoma treated with mediastinal irradiation, Blood 117 (2) (2011) 412-418, https://doi.org/10.1182/blood-2010-06-291328.

[17] K. Wang, K.A. Pearlstein, N.D. Patchett, A.M. Deal, P. Mavroidis, B.C. Jensen, M. B. Lipner, T.M. Zagar, Y. Wang, C.B. Lee, M.J. Eblan, J.G. Rosenman, M. A. Socinski, T.E. Stinchcombe, L.B. Marks, Heart dosimetric analysis of three types of cardiac toxicity in patients treated on dose-escalation trials for Stage III nonsmall-cell lung cancer, Radiother. Oncol.: J. Eur. Soc. Therapeut. Radiol. Oncol. 125 (2) (2017) 293-300, https://doi.org/10.1016/j.radonc.2017.10.001.

[18] J.L. Zamorano, P. Lancellotti, D. Rodriguez Munoz, V. Aboyans, R. Asteggiano, M. Galderisi, G. Habib, D.J. Lenihan, G.Y.H. Lip, A.R. Lyon, T. Lopez Fernandez, D. Mohty, M.F. Piepoli, J. Tamargo, A. Torbicki, T.M. Suter, 2016 ESC Position Paper on cancer treatments and cardiovascular toxicity developed under the auspices of the ESC Committee for Practice Guidelines: The Task Force for cancer treatments and cardiovascular toxicity of the European Society of Cardiology (ESC), Eur. Heart J. 37 (36) (2016) 2768-2801, https://doi.org/10.1093/ eurheartj/ehw211.

[19] P. Loap, V. Servois, G. Dhonneur, K. Kirov, A. Fourquet, Y. Kirova, A radiotherapy contouring atlas for cardiac conduction node delineation, Pract. Radiat. Oncol. (2021), https://doi.org/10.1016/j.prro.2021.02.002.

[20] M. Zecchin, M. Torre, E. Carrani, L. Sampaolo, E. Ciminello, B. Ortis, R. Ricci, A. Proclemer, G. Sinagra, G. Boriani, Seventeen-year trend (2001-2017) in pacemaker and implantable cardioverter-defibrillator utilization based on hospital discharge database data: An analysis by age groups, Eur. J. Internal Med. 84 (2021) 38-45, https://doi.org/10.1016/j.ejim.2020.09.003. 